(6)

OPEN ACCESS

\title{
Prevalence and correlates of 'sexual competence' at first heterosexual intercourse among young people in Britain
}

\author{
Melissa J Palmer, ${ }^{1}$ Lynda Clarke, ${ }^{1}$ George B Ploubidis, ${ }^{2}$ Kaye Wellings ${ }^{3}$
}

\begin{abstract}
'Department of Population Health, London School of Hygiene and Tropical Medicine, London, UK

${ }^{2}$ Department of Social Science, UCL Institute of Education, University College London, London, UK

${ }^{3}$ Department of Public Health, Environments and Society, London School of Hygiene and Tropical Medicine, London, UK
\end{abstract}

\section{Correspondence to} Dr Melissa J Palmer, Department of Population Health, London School of Hygiene and Tropical Medicine, London WC1E 7HT, UK; Melissa.Palmer@|shtm.ac.uk

Received 12 June 2018 Revised 19 November 2018 Accepted 10 December 2018 Published Online First 14 January 2019
Check for updates

(C) Author(s) (or their employer(s)) 2019. Re-use permitted under CC BY. Published by BMJ.

To cite: Palmer MJ, Clarke L, Ploubidis GB, et al. BMJ Sex Reprod Health

2019;45:127-137.

\begin{abstract}
Background A greater understanding of the circumstances of first sexual intercourse, as opposed to an exclusive focus on age at occurrence, is required in order that sexual health and well-being can be promoted from the onset of sexual activity.

Methods We used data from the third National Survey of Sexual Attitudes and Lifestyles (Natsal-3) conducted in Britain. Participants were categorised as 'sexually competent' at first heterosexual intercourse if the following self-reported criteria applied to the event: contraceptive use, autonomy of decision, both partners 'equally willing', and occurrence at the perceived 'right time'. We examined the prevalence of 'sexual competence', and its component parts, by age at first intercourse among 17-24-year-olds. Using multivariable logistic regression, we explored associations between sexual competence and potential explanatory factors.
\end{abstract}

Results Variation in 'sexual competence' and its component parts was associated with, but not fully explained by, age at first sex: $22.4 \%$ and $36.2 \%$ of men and women who had first sex at age 13-14 years were categorised as 'sexually competent', rising to $63.7 \%$ and $60.4 \%$ among those aged $\geq 18$ years at first intercourse. Lack of sexual competence was independently associated with: first intercourse before the age of 16 years, area-level deprivation (men only), lower educational level, black ethnicity (women only), reporting 'friends' as main source of learning about sex (women only), non-'steady' relationship at first sex, and uncertainty of first partner's virginity status.

Conclusions A substantial proportion of young people in Britain transition into sexual activity under circumstances incompatible with positive sexual health. Social inequalities in sexual health are reflected in the context of first intercourse.

\section{Key messages}

- A substantial proportion of young people in Britain transition into sexual activity under circumstances that are incompatible with positive sexual health.

- Adverse circumstances of first sexual intercourse were associated with socioeconomic status, educational level, source of sex education, relationship with, and virginity status of, the first partner.

- An exclusive focus on chronological age neglects the importance of contextual circumstances in defining the nature of first sexual intercourse.

\section{INTRODUCTION}

The context in which first sexual intercourse occurs generally receives less empirical attention than chronological age at first sexual intercourse. However, an exclusive focus on age neglects individual differences in physical, social and psychological maturity, as well as the emphasis placed by young people themselves on the circumstances in which first sex occurred in evaluating their experiences. ${ }^{1}$ As a result, some have argued for a more nuanced concept of readiness and appropriateness of timing of first sexual intercourse. $^{2}$

The concept of 'sexual competence' represents an alternative approach to timing of first sexual intercourse, considering the contextual attributes of the event, rather than simply age at occurrence. This departs from the traditional framing of all sexual activity among teenagers as problematic, and recognises that young age alone does not threaten sexual health, any more than older age safeguards it. ${ }^{3}$ With reference to prior work on the role 
of 'interactional competence' in negotiating sexual behaviour, ${ }^{45}$ 'sexual competence' was operationalised specifically in relation to first heterosexual intercourse by Wellings et $a l^{6}$ using four variables measured in the second National Survey of Sexual Attitudes and Lifestyles (Natsal-2). Participants were classified as 'sexually competent' at first intercourse if they reported that the event was characterised by contraceptive protection, autonomy of decision, equal willingness of both partners, and that it had occurred at the 'right time'.

The use of these domains in defining sexual competence may be considered compatible with the definition of sexual health endorsed by the $\mathrm{WHO},{ }^{7}$ highlighting the importance of not only physical health, but also mental and social aspects, referring to a "positive and respectful approach to...sexual relationships" and "safe sexual experiences, free of coercion".

In this study, we examined the prevalence of 'sexual competence' and its component variables in a representative population-based sample of 17-24-year-olds living in Britain. Further, we examined the antecedent factors that are associated with a lack of 'sexual competence' at first sexual intercourse. The public health relevance of this study is two-fold. First, given its compatibility with the WHO definition of sexual health, the concept of sexual competence is likely to represent first sexual intercourse that is consistent with well-being and health. Second, studies have shown that psychosocial factors relating to first intercourse, such as autonomy and the emotional experience, are associated with sexual health outcomes. ${ }^{8-10}$ We have shown lack of sexual competence at first sex (the term 'sex' is used specifically in relation to heterosexual intercourse unless explicitly stated otherwise) to be associated with poor subsequent sexual health, as defined by self-reported sexually transmitted infection (STI) diagnosis, testing positive for human papillomavirus (HPV), lower sexual function, unplanned pregnancy, and experience of non-volitional sex. ${ }^{11}$

\section{METHODS}

\section{Participants}

The Third National Survey of Sexual Attitudes and Lifestyles (Natsal-3) is a stratified probability sample survey of 15162 men and women aged 16-74 years, resident in Britain, conducted in 2010-2012. ${ }^{12}$ We restricted analyses to sexually experienced respondents aged $17-24$ years $(n=2825)$ to ensure relevancy to the recent cohort becoming sexually active in Britain. In order to examine the relationship between education and sexual competence, participants aged 16 years at interview were excluded because they could not be ascribed an educational level.

\section{Measures}

Participants were asked about their age at and experience of first heterosexual intercourse in the faceto-face component of the interview. These questions were asked with the use of show cards so that respondents did not have to verbalise any sexually explicit terms, instead quoting the letter that corresponded to their preferred answer option, and to help preserve confidentiality (in case of being overheard by other household members). For participants reporting first sexual intercourse at age 12 years or younger, questions about circumstances were asked about their first experience since turning age 13 years due to ethical concerns relating to probing questions about early non-consensual encounters. ${ }^{12}$ The questions relating to the experience of first intercourse sought to measure whether partners were both equally willing to engage in sexual intercourse; whether the decision to have sex was autonomous (not due to factors external to the self, such as peer pressure or drunkenness); whether the respondent felt their first experience of sexual intercourse had happened at the 'right' time; and whether a reliable method of contraception had been used (contraceptive pill or condom) (survey questions have been previously reported). ${ }^{11}$ As in the study by Wellings et $a l,{ }^{6}$ the measure of sexual competence constructed using these four variables was as follows: respondents who endorsed all four of these items were categorised as 'sexually competent' at first intercourse, and respondents who endorsed fewer than all four were categorised as not 'sexually competent' at first intercourse. Respondents reporting that their partner was 'more willing' at first sex were filtered to an additional question asking whether they were 'forced'. Those reporting forced first sex were excluded from analyses $(n=22)$ as it was considered inappropriate to classify these respondents in terms of 'sexual competence'.

Potential explanatory variables were selected with the aim of representing key influences in childhood and adolescence, along with those relating to the more immediate context of first sex. Two indicators relating to socio-economic status were examined: the area-level Index of Multiple Deprivation quintiles, ${ }^{13}$ and educational level of the participant. The ethnicity of participants, and their family structure (whether they lived with both parents) at age 14 years, provided further contextual information. Two variables relating to learning about sexual matters, which potentially have a more direct influence on sexual behaviour, were examined: one based on a question asking participants to identify the 'main' source from which they learnt about sexual matters when growing up; the other asked about the level/difficulty of discussing sex with their parents during their teenage years. Finally, factors relating to the immediate context of first sexual intercourse were explored, including the nature of the relationship, the age of the participant at first sex and how this compared with the age of the partner, and the prior sexual experience of the partner. 


\section{Statistical analysis}

We present the prevalence of 'sexual competence', and the measure's component parts by age at first sexual intercourse. Unadjusted odds ratios were calculated to examine variation in the prevalence of 'sexual competence' at first sex by potential explanatory factors.

Multivariable logistic regression was used to determine which factors were independently associated with 'sexual competence' at first sex. Two multivariable regression models are presented. The first model includes the variables relating to socio-demographic background factors, how the respondent learnt about sex, age at first sex. The second model also includes the variables indicative of the relationship context in which first sex occurred. This two-stage approach was employed in order that we could examine the independent associations between sexual competence and the variables conceptualised as more distally related to the outcome, before separately evaluating the variables considered to be more proximal to event, adjusted for those at more distal levels. All analyses were conducted using the Stata (Version 13) survey commands, accounting for the weighting, clustering and stratification of the survey data.

Patient and public involvement

Patients were not involved in this study.

\section{RESULTS}

\section{Prevalence and unadjusted odds ratios}

Table 1 shows the proportion of 17-24-year-old respondents who reported the following conditions of first intercourse: unequal willingness; a non-autonomous decision; that sex had not happened at the 'right time'; and non-use of contraception, by gender and age at first sexual intercourse. The most commonly reported negative feature of first sex was that it was not felt to have occurred at the 'right time' (39.7\% of women and $26.5 \%$ of men). Approximately $10 \%$ of young people did not use a reliable contraceptive method at first sex. Among women, a general pattern was observed whereby those who were younger at first sex more commonly reported adverse contextual factors, with statistically significant trends observed for perceived timing, equal willingness, and

Table 1 Proportion of 17-24-year-olds reporting certain circumstances at first sex by age at first sex

\begin{tabular}{|c|c|c|c|c|c|c|}
\hline \multirow{2}{*}{$\begin{array}{l}\text { Age at first sex } \\
\text { (years) }\end{array}$} & \multirow{2}{*}{$\begin{array}{l}\text { Not equally } \\
\text { willing }\end{array}$} & \multirow{2}{*}{$\begin{array}{l}\text { Not the 'right } \\
\text { time' } \\
\%(95 \% \mathrm{Cl})\end{array}$} & \multirow{2}{*}{$\begin{array}{l}\begin{array}{l}\text { Non-autonomous } \\
\text { reason }\end{array} \\
\%(95 \% \mathrm{Cl})\end{array}$} & \multirow{2}{*}{$\begin{array}{l}\text { Did not use } \\
\text { reliable } \\
\text { contraception } \\
\%(95 \% \mathrm{Cl}) \\
\end{array}$} & \multirow{2}{*}{$\begin{array}{l}\text { Not 'sexually } \\
\text { competent' } \\
\%(95 \% \mathrm{Cl})\end{array}$} & \multirow{2}{*}{$\begin{array}{l}\mathrm{N} \\
\text { (unweighted/ } \\
\text { weighted)* }\end{array}$} \\
\hline & & & & & & \\
\hline \multicolumn{7}{|l|}{ Women } \\
\hline $13-14$ & 28.4 (22.7 to 34.9$)$ & 71.6 (65.2 to 77.2 ) & 28.8 (23.2 to 35.0$)$ & 17.4 (13.0 to 22.8$)$ & 77.7 (71.5 to 82.9) & 249/119 \\
\hline 15 & $16.0(12.4$ to 20.4$)$ & 53.8 (48.1 to 59.5) & 23.6 (19.0 to 28.8$)$ & $10.2(7.4$ to 13.9$)$ & 61.5 (55.7 to 66.9$)$ & $352 / 185$ \\
\hline 16 & 15.7 (12.1 to 20.7$)$ & 30.8 (26.2 to 35.8$)$ & $13.9(10.8$ to 17.8$)$ & 6.8 (4.8 to 9.5$)$ & 44.9 (39.8 to 50.0$)$ & $473 / 260$ \\
\hline 17 & $17.9(12.4$ to 25.0$)$ & 31.4 (25.2 to 38.4$)$ & 14.3 (10.2 to 19.6$)$ & $10.9(7.2$ to 16.2$)$ & 47.6 (40.7 to 54.6 ) & $262 / 152$ \\
\hline $18-24$ & $13.4(9.0$ to 19.4$)$ & 22.1 (16.3 to 29.3$)$ & $7.7(4.4$ to 13.1$)$ & $11.3(7.5$ to 16.7$)$ & 36.3 (29.3 to 44.0$)$ & $227 / 163$ \\
\hline$P$ valuet & 0.009 & $<0.001$ & $<0.001$ & 0.234 & $<0.001$ & \\
\hline All & 17.4 (15.4 to 19.7$)$ & 39.7 (37.0 to 42.4 ) & $17.0(15.1$ to 19.1$)$ & $10.5(8.9$ to 12.3$)$ & 51.7 (48.9 to 54.5$)$ & \\
\hline $\begin{array}{l}\mathrm{N} \text { (unweighted/ } \\
\text { weighted) }\end{array}$ & $1567 / 880$ & $1562 / 877$ & $1543 / 865$ & $1566 / 880$ & $1563 / 878$ & \\
\hline \multicolumn{7}{|l|}{ Men } \\
\hline $13-14$ & 16.6 (11.1 to 24.1$)$ & 49.0 (41.4 to 56.6$)$ & 14.6 (9.5 to 21.6$)$ & $25.0(19.2$ to 31.9$)$ & 64.7 (57.3 to 71.5$)$ & $210 / 148$ \\
\hline 15 & $8.0(5.0$ to 12.4$)$ & 29.6 (23.8 to 36.0$)$ & 15.3 (11.4 to 20.4$)$ & $10.9(7.4$ to 15.8$)$ & 47.3 (40.7 to 53.9$)$ & $262 / 186$ \\
\hline 16 & $6.7(4.1$ to 10.8$)$ & 20.1 (15.1 to 26.2 ) & $11.4(8.0$ to 16.1$)$ & 5.7 (3.5 to 8.9$)$ & 34.3 (28.5 to 40.6$)$ & $318 / 234$ \\
\hline 17 & 13.1 (7.6 to 21.6$)$ & 15.6 (10.7 to 22.2$)$ & 7.9 (4.7 to 12.8$)$ & 9.5 (6.1 to 14.5$)$ & 38.0 (30.7 to 46.0$)$ & $214 / 160$ \\
\hline $18-24$ & $7.4(4.6$ to 11.6$)$ & $23.0(16.8$ to 30.6$)$ & $12.4(8.3$ to 18.1$)$ & $12.8(8.6$ to 18.6$)$ & 39.6 (32.3 to 47.3$)$ & $217 / 180$ \\
\hline$P$ valuet & 0.133 & $<0.001$ & 0.161 & 0.014 & $<0.001$ & \\
\hline All & 9.8 (7.9 to 12.2$)$ & 26.5 (23.8 to 29.5 ) & $12.3(10.3$ to 14.6$)$ & $12.0(10.2$ to 14.1$)$ & 43.6 (40.4 to 46.9$)$ & \\
\hline $\begin{array}{l}\mathrm{N} \text { (unweighted/ } \\
\text { weighted) } \ddagger\end{array}$ & $1226 / 912$ & $1218 / 906$ & $1221 / 908$ & $1225 / 911$ & $1221 / 908$ & \\
\hline
\end{tabular}


non-autonomous decision-making. Among men, such a trend was observed for perceived timing and contraceptive use. Some $77.7 \%$ of women and $64.7 \%$ of men who reported first intercourse at age 13-14 years were categorised as not 'sexually competent', declining to $36.3 \%$ and $39.6 \%$ among those aged $\geq 18$ years at first intercourse.

Table 2 shows the prevalence and unadjusted odds ratios of a lack of sexual competence at first sex according to potential explanatory factors. Among both men and women, lack of sexual competence was associated with: living in a more deprived area; lower education level; not living with both parents at age 14 years; first sex occurring before age 16 years; reporting having not been in a 'steady' relationship at first sex; the virginity status of the first sexual partner (with the highest odds of lacking sexual competence among those who were uncertain of their partner's virginity status); and having an older first sexual partner. Among women only, a lack of sexual competence was also associated with black ethnicity; reporting 'friends' or 'other' as the main source of learning about sexual matters while growing up; and lack of discussion with parents about sexual matters when growing up.

\section{Multivariable regression analyses}

The results of multivariable logistic regression analyses are presented in tables 3 and 4 . The first model (Model 1) includes the variables relating to socio-demographic background factors, how the respondent learnt about sex, and age at first sex. In these adjusted models, the majority of associations observed in the crude analyses were retained, although somewhat attenuated. (Model 1 , tables 3 and 4).

After adjustment for variables relating to the immediate relational context in which first intercourse occurred (Model 2, table 4), source of learning about sexual matters and communication with parents about sexual matters were no longer associated with sexual competence among women, potentially indicating a mediatory role of these more proximal factors. Lower educational level, black ethnicity, and sex before 16 years retained their associations with a lack of sexual competence at first sex among women, although at a borderline level for the former. Among men, the associations between a sexual competence and IMD quintile, educational level, and sex before 16 retained statistical significance, even after adjustment for the variables relating to the immediate relational context of first sex (Model 2, table 3).

After adjustment for all other variables in the model, the status of the relationship with the first sexual partner retained its strong associations with sexual competence (Model 2, tables 2 and 3). Among men, this association seemed primarily driven by the increased odds of a lack of sexual competence among those reporting they 'had just/recently met' their partner compared with those in a 'steady relationship' at the time. Respondents' knowledge of their first sexual partner's virginity status also continued to be associated with sexual competence among women after adjustment. A similar association, of borderline statistical significance, was also evident among men. Finally, having had an older partner at first sex was no longer associated with lacking sexual competence among men or women in these fully adjusted models.

\section{DISCUSSION}

This study describes the circumstances of first sexual intercourse using a representative population-based sample of young people living in Britain, and provides an exploration of the antecedent factors associated with a novel measure of the first sexual intercourse experience: 'sexual competence'.

Adverse circumstances of first sex were reported by a substantial proportion of young people. More than a third of women and a quarter of men did not consider that their experience of first sexual intercourse occurred at the 'right time', while almost 1 in 5 women reported that they and their partner were not equally willing to have sex on that first occurrence, and a similar proportion of women reported a non-autonomous reason for first sex. While the majority of young people used a reliable contraceptive method at first sex, 1 in 10 did not.

In relation to the composite measure of 'sexual competence', over half of women and more than a third of men were categorised as not being 'sexually competent' at first sex. Although age at first intercourse was associated with sexual competence, it did not explain all of the variability in sexual competence - at no age did the prevalence of sexual competence approach zero or $100 \%$. This finding supports the proposition that chronological age may be an overly simplistic indicator of the nature of first intercourse. Furthermore, the associations between several antecedent factors and sexual competence at first sex were retained when adjusting for age at first sex. This provides further evidence that the measure of sexual competence represents a distinct dimension of the experience of first intercourse, which is not simply a function of age.

In line with previous research, the stability of the partnership was associated with a more positive first sexual experience. ${ }^{14-17}$ Uncertainty relating to the virginity status of the partner was associated with a lack of sexual competence, potentially suggesting this variable is acting as a proxy for communication between partners. The association between indicators of socio-economic status and sexual competence is consistent with previous research ${ }^{6} 151819$ and may be explained by the effect of limited life aspirations on sexual behaviour. ${ }^{18} 20$ Previous research has found that individuals of lower socio-economic status have lower levels of perceived control, ${ }^{21} 22$ which could be an important psycho-social determinant of sexual 


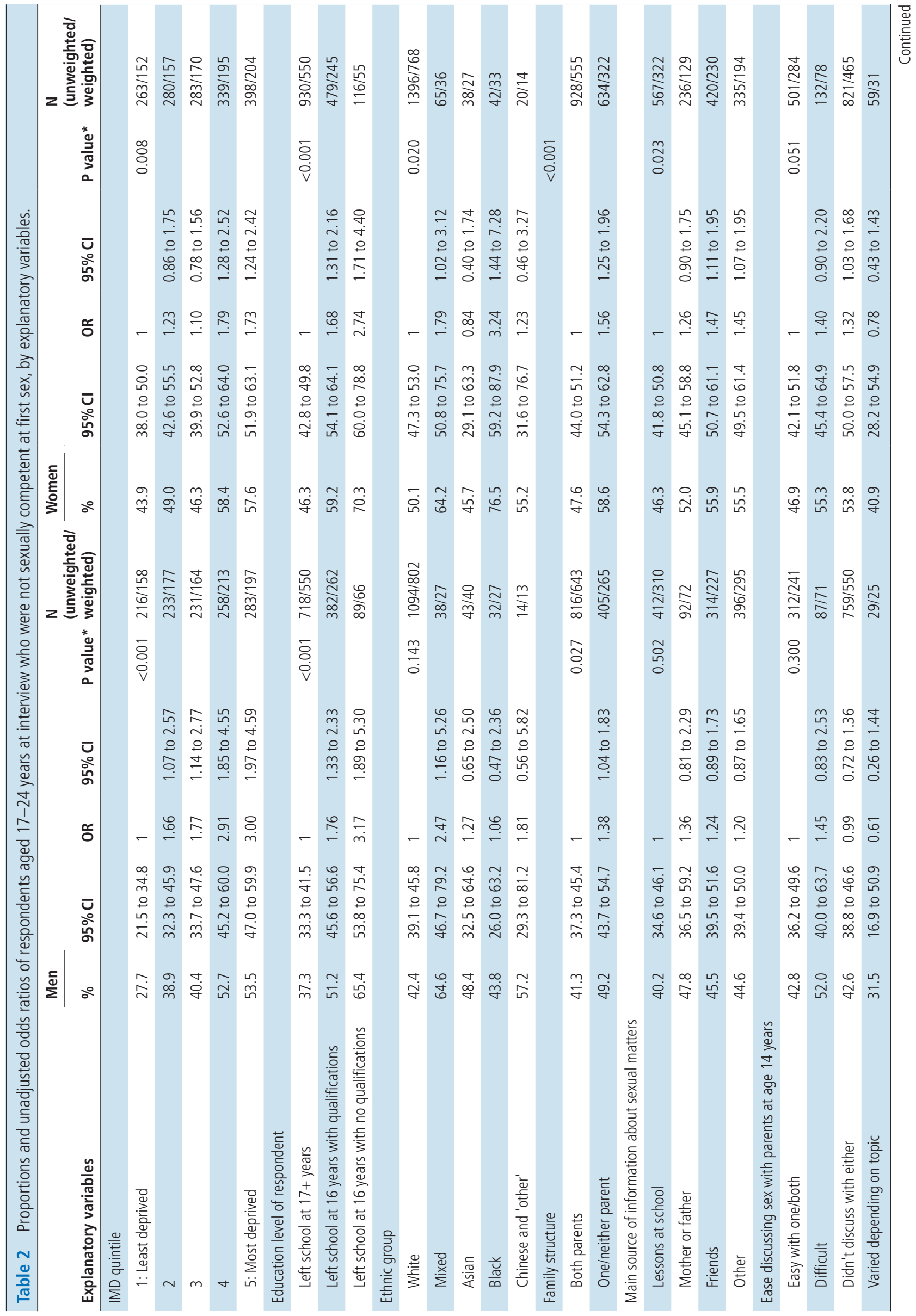




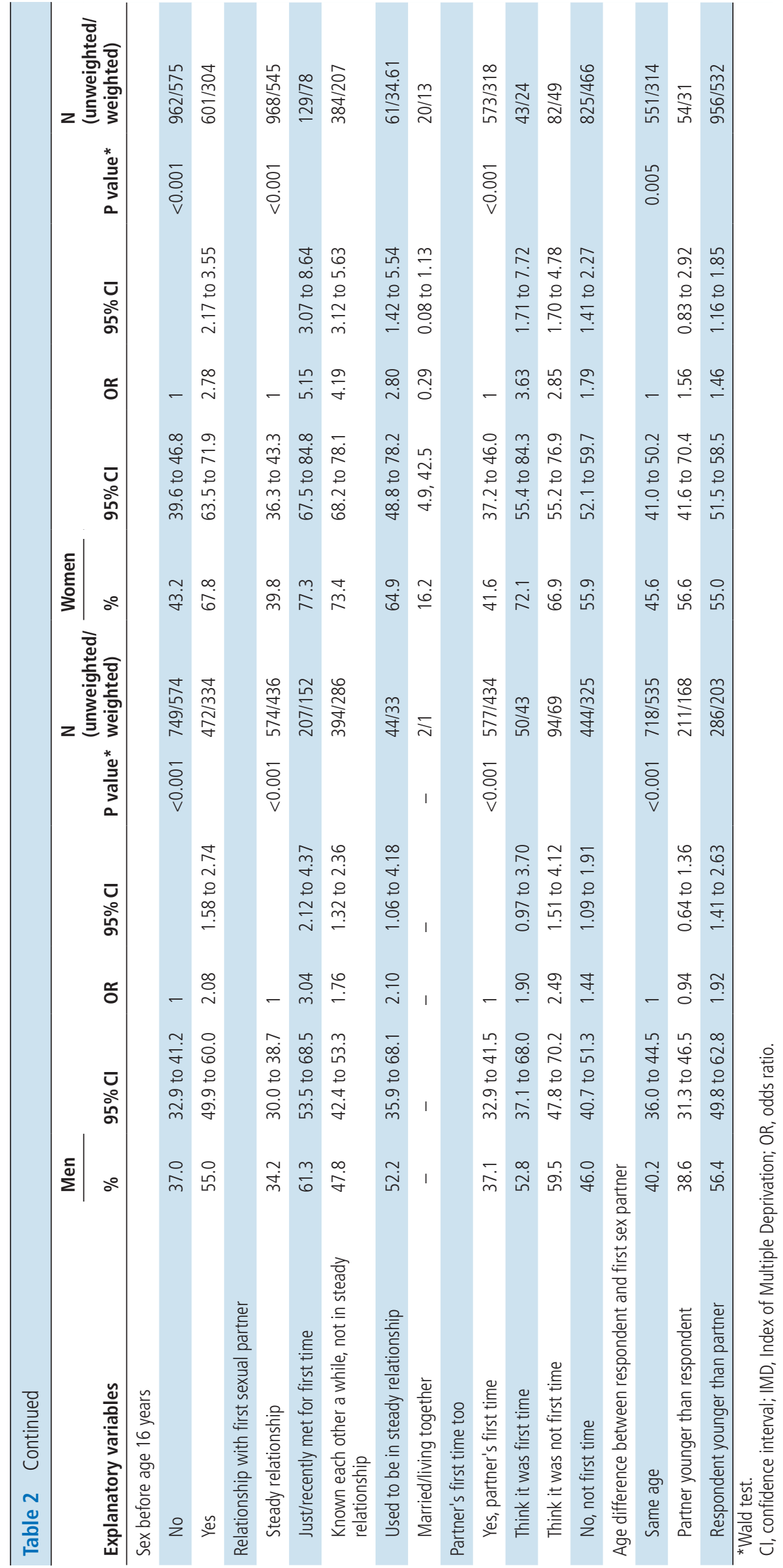


Table 3 Logistic regression examining predictors of lack of sexual competence at first sex, results adjusted for all other variables in table column (Men)

\begin{tabular}{|c|c|c|c|c|c|c|}
\hline \multirow[b]{2}{*}{ Outcome: not sexually competent at first intercourse } & \multicolumn{3}{|c|}{ Model 1} & \multicolumn{3}{|c|}{ Model 2} \\
\hline & AOR & $95 \% \mathrm{Cl}$ & $P$ value & AOR & $95 \% \mathrm{Cl}$ & $P$ value \\
\hline \multicolumn{7}{|l|}{ IMD quintile } \\
\hline 1: Least deprived & 1 & & 0.003 & 1 & & 0.006 \\
\hline 2 & 1.58 & 1.00 to 2.48 & & 1.49 & 0.95 to 2.34 & \\
\hline 3 & 1.64 & 1.03 to 2.62 & & 1.55 & 0.97 to 2.47 & \\
\hline 4 & 2.43 & 1.51 to 3.92 & & 2.29 & 1.44 to 3.63 & \\
\hline 5: Most deprived & 2.21 & 1.40 to 3.48 & & 2.03 & 1.28 to 3.22 & \\
\hline \multicolumn{7}{|l|}{ Education level of respondent } \\
\hline Studying for/attained further academic qualifications & 1 & & 0.002 & 1 & & 0.047 \\
\hline No academic qualifications & 2.36 & 1.32 to 4.22 & & 2.27 & 1.25 to 4.13 & \\
\hline Academic qualifications typically gained at age 16 years & 1.54 & 1.12 to 2.12 & & 1.49 & 1.08 to 2.05 & \\
\hline \multicolumn{7}{|l|}{ Ethnic group } \\
\hline White & 1 & & 0.136 & 1 & & 0.130 \\
\hline Mixed & 2.84 & 1.18 to 6.84 & & 2.88 & 1.12 to 7.41 & \\
\hline Asian & 1.49 & 0.73 to 3.05 & & 1.71 & 0.82 to 3.58 & \\
\hline Black & 0.75 & 0.31 to 1.82 & & 0.75 & 0.30 to 1.87 & \\
\hline Chinese and 'other' & 0.84 & 0.13 to 5.46 & & 0.85 & 0.10 to 7.24 & \\
\hline \multicolumn{7}{|l|}{ Family structure } \\
\hline Both parents & 1 & & 0.957 & 1 & & \\
\hline One/neither parent & 0.99 & 0.72 to 1.36 & & 1.01 & 0.74 to 1.39 & 0.935 \\
\hline \multicolumn{7}{|l|}{ Main source of information about sexual matters } \\
\hline Lessons at school & 1 & & 0.646 & 1 & & 0.754 \\
\hline Mother or father & 1.29 & 0.69 to 2.42 & & 1.22 & 0.67 to 2.22 & \\
\hline Friends & 1.00 & 0.70 to 1.43 & & 0.95 & 0.66 to 1.37 & \\
\hline Other & 0.88 & 0.62 to 1.25 & & 0.89 & 0.62 to 1.27 & \\
\hline \multicolumn{7}{|l|}{ Ease discussing sex with parents at age 14 years } \\
\hline Easy with one/both & 1 & & 0.272 & 1 & & 0.197 \\
\hline Difficult & 1.65 & 0.87 to 3.13 & & 1.66 & 0.87 to 3.17 & \\
\hline Didn't discuss with either & 0.99 & 0.69 to 1.43 & & 0.96 & 0.67 to 1.38 & \\
\hline Varied depending on topic & 0.72 & 0.31 to 1.70 & & 0.64 & 0.28 to 1.46 & \\
\hline \multicolumn{7}{|l|}{ Sex before age 16} \\
\hline No & 1 & & $<0.001$ & 1 & & 0.001 \\
\hline Yes & 1.72 & 1.27 to 2.34 & & 1.71 & 1.24 to 2.36 & \\
\hline \multicolumn{7}{|l|}{ Relationship with first sexual partner } \\
\hline Steady relationship & & & & 1 & & $<0.001$ \\
\hline Just/recently met for first time & & & & 2.42 & 1.57 to 3.73 & \\
\hline Known each other a while to not in steady relationship & & & & 1.15 & 0.81 to 1.62 & \\
\hline Used to be in steady relationship & & & & 1.56 & 0.66 to 3.70 & \\
\hline Married/living together & & & & - & - & - \\
\hline \multicolumn{7}{|l|}{ Partner's first time too } \\
\hline Yes to partner's first time & & & & 1 & & 0.0639 \\
\hline Think it was first time & & & & 1.75 & 0.87 to 3.53 & \\
\hline Think it was not first time & & & & 2.12 & 1.15 to 3.91 & \\
\hline No to not first time & & & & 1.19 & 0.84 to 1.67 & \\
\hline
\end{tabular}


Table 3 Continued

\begin{tabular}{|c|c|c|c|c|c|c|}
\hline \multirow[b]{2}{*}{ Outcome: not sexually competent at first intercourse } & \multicolumn{3}{|c|}{ Model 1} & \multicolumn{3}{|c|}{ Model 2} \\
\hline & AOR & $95 \% \mathrm{Cl}$ & $P$ value & AOR & $95 \% \mathrm{Cl}$ & $P$ value \\
\hline \multicolumn{7}{|l|}{ Age difference between respondent and first sex partner } \\
\hline Same age & & & & 1 & & 0.4316 \\
\hline Partner younger than respondent & & & & 0.94 & 0.63 to 1.41 & \\
\hline Respondent younger than partner & & & & 1.25 & 0.86 to 1.80 & \\
\hline $\mathrm{N}$ unweighted & & & 1092 & & & 1092 \\
\hline N weighted & & & 817 & & & 817 \\
\hline
\end{tabular}

AOR, adjusted odds ratio; $C l$, confidence interval; IMD, Index of Multiple Deprivation.

competence. The association between ethnicity and sexual competence is consistent with previous research reporting variations in sexual behaviour across different ethnic groups, as is the finding that the association remains after adjustment for broader risk factors (eg, indicators of socio-economic status). ${ }^{23}$ Further research is warranted to examine the drivers of ethnic variations in sexual behaviour and health.

That young women who had discussed sexual matters with their parents, and those who reported school to be their main source from which they learnt about sexual matters, were more likely to have been sexually competent at first sex resonates with previous research. ${ }^{64}$ Parental communication, and school-based relationships and sex education, may provide the knowledge and skills required to negotiate a positive and safe sexual experience. However, these associations were not observed among men, even in unadjusted analyses. A possible interpretation is that communication and negotiation skills are less important for men in achieving a first sexual intercourse that they reflect positively on. Prior research reports that men generally give more positive accounts of first intercourse as they are more likely to just be happy that they had $\operatorname{sex}^{25} 26$ and less likely to report experiencing pressure from their partner. ${ }^{25} 27$

\section{Limitations}

The response rate to Natsal-3, at $57.7 \%,{ }^{12}$ potentially limits representativeness of the findings. Our reliance on observational data means that the associations detected may be due to unmeasured and/or unknown confounders. The Natsal survey relies on retrospective self-reports relating to an event that could have occurred up to a decade earlier; therefore, it is important to consider the potential for recall bias when interpreting the results. This could explain the strong association observed between relationship with partner at first sex and sexual competence at first sex; perhaps those who reflect on the first sexual intercourse positively, and therefore will be classified at sexually competent, will also be more likely to recall that they were in a 'steady' relationship at the time. Finally, despite Natsal-3's large sample size, a relatively small proportion of participants were of non-white British ethnicity (reflecting the ethnic composition of Britain), meaning that analyses involving specific ethnic groups were limited by small numbers.

\section{CONCLUSIONS AND IMPLICATIONS}

A substantial proportion of young people in Britain become sexually active under circumstances that are arguably incompatible with sexual health defined in its broad sense encompassing both physical and psycho-social well-being.

The antecedent factors associated with sexual competence are of public health relevance for understanding where interventions to improve the conditions of first sex may be best targeted. Inequalities in sexual health have commonly been described in terms of the unequal distributions of STIs, ${ }^{28}$ unplanned pregnancies, ${ }^{29}$ and 'early' transitions into sexual activity, ${ }^{30}$ across socio-economic groups. The current findings suggest that these inequalities are also reflected in the nature of first intercourse, indicating that greater efforts are required to reduce the disparities that exist from the very onset of sexual activity. While the results indicate that communication with parents about sex and school-based sex education may help towards the achievement of sexual competence among young women, the same cannot be said for men, suggesting that greater consideration needs to be given to how men can best be equipped to have a safe and positive transition into sexual activity.

Previous research has suggested that the experience of first sexual intercourse can have implications for sexual health status later in life. ${ }^{8-10}$ Analyses of Natsal-3 data have identified lack of sexual competence at first intercourse to be a risk factor for poor subsequent sexual health among young people, independently of age at first sex..$^{11}$ Therefore, it is possible that targeted interventions aimed at enabling at-risk young people to have a more positive and healthy first sexual experience may result in improvements in sexual health that continue into adulthood.

As a research tool, the measure of sexual competence was constructed rather opportunistically by 
Table 4 Logistic regression examining predictors of lack of sexual competence at first sex, results adjusted for all other variables in table column (Women)

\begin{tabular}{|c|c|c|c|c|c|c|}
\hline \multirow[b]{2}{*}{ Outcome: not sexually competent at first intercourse } & \multirow[b]{2}{*}{ AOR } & \multirow{2}{*}{$\begin{array}{l}\text { Model } 1 \\
95 \% \mathrm{Cl}\end{array}$} & \multirow[b]{2}{*}{$P$ value } & \multirow[b]{2}{*}{ AOR } & \multirow{2}{*}{$\begin{array}{l}\text { Model } 2 \\
95 \% \mathrm{Cl}\end{array}$} & \multirow[b]{2}{*}{$P$ value } \\
\hline & & & & & & \\
\hline \multicolumn{7}{|l|}{ IMD quintile } \\
\hline 1: Least deprived & 1 & & 0.233 & 1 & & 0.291 \\
\hline 2 & 1.19 & 0.81 to 1.74 & & 1.18 & 0.78 to 1.78 & \\
\hline 3 & 0.99 & 0.68 to 1.43 & & 0.96 & 0.64 to 1.44 & \\
\hline 4 & 1.44 & 0.99 to 2.07 & & 1.43 & 0.97 to 2.12 & \\
\hline 5: Most deprived & 1.26 & 0.87 to 1.82 & & 1.22 & 0.83 to 1.81 & \\
\hline \multicolumn{7}{|l|}{ Education level of respondent } \\
\hline Studying for/attained further academic qualifications & 1 & & 0.020 & 1 & & 0.067 \\
\hline Academic qualifications typically gained at 16 years & 1.34 & 1.02 to 1.76 & & 1.22 & 0.91 to 1.63 & \\
\hline No academic qualifications & 1.81 & 1.07 to 3.08 & & 1.87 & 1.06 to 3.32 & \\
\hline \multicolumn{7}{|l|}{ Ethnic group } \\
\hline White & 1 & & 0.050 & 1 & & 0.009 \\
\hline Mixed & 1.75 & 0.87 to 3.52 & & 1.47 & 0.74 to 2.93 & \\
\hline Asian & 1.54 & 0.67 to 3.52 & & 2.85 & 1.10 to 7.41 & \\
\hline Black & 3.22 & 1.26 to 8.22 & & 4.67 & 1.62 to 13.45 & \\
\hline Chinese and 'other' & 1.66 & 0.60 to 4.58 & & 2.97 & 0.80 to 11.01 & \\
\hline \multicolumn{7}{|l|}{ Family structure } \\
\hline Both parents & 1 & & 0.029 & 1 & & 0.245 \\
\hline One/neither parent & 1.34 & 1.03 to 1.73 & & 1.18 & 0.89 to 1.56 & \\
\hline \multicolumn{7}{|l|}{ Main source of information about sexual matters } \\
\hline Lessons at school & 1 & & 0.071 & 1 & & 0.536 \\
\hline Mother or father & 1.38 & 0.92 to 2.09 & & 1.33 & 0.85 to 2.09 & \\
\hline Friends & 1.48 & 1.09 to 2.02 & & 1.20 & 0.86 to 1.67 & \\
\hline Other & 1.25 & 0.90 to 1.72 & & 1.15 & 0.80 to 1.64 & \\
\hline \multicolumn{7}{|l|}{ Ease discussing sex with parents at age 14 years } \\
\hline Easy with one/both & 1 & & 0.096 & 1 & & 0.137 \\
\hline Difficult & 1.58 & 0.93 to 2.67 & & 1.51 & 0.90 to 2.54 & \\
\hline Didn't discuss with either & 1.39 & 1.02 to 1.90 & & 1.39 & 0.98 to 1.95 & \\
\hline Varied depending on topic & 0.94 & 0.50 to 1.77 & & 0.91 & 0.47 to 1.76 & \\
\hline \multicolumn{7}{|l|}{ Sex before age 16 years } \\
\hline No & 1 & & $<0.001$ & 1 & & $<0.001$ \\
\hline Yes & 2.60 & 2.00 to 3.38 & & 2.93 & 2.20 to 3.90 & \\
\hline \multicolumn{7}{|l|}{ Relationship with first sexual partner } \\
\hline Steady relationship & & & & 1 & & $<0.001$ \\
\hline Just/recently met for first time & & & & 4.84 & 2.71 to 8.64 & \\
\hline Known each other a while to not in steady relationship & & & & 3.95 & 2.81 to 5.56 & \\
\hline Used to be in steady relationship & & & & 2.95 & 1.45 to 6.01 & \\
\hline Married/living together & & & & 0.14 & 0.02 to 1.21 & \\
\hline \multicolumn{7}{|l|}{ Partner's first time too } \\
\hline Yes to partner's first time & & & & 1 & & $<0.001$ \\
\hline Think it was first time & & & & 3.90 & 1.62 to 9.36 & \\
\hline Think it was not first time & & & & 2.29 & 1.21 to 4.34 & \\
\hline No to not first time & & & & 1.52 & 1.14 to 2.04 & \\
\hline
\end{tabular}




\begin{tabular}{|c|c|c|c|c|c|}
\hline \multirow[b]{2}{*}{ Outcome: not sexually competent at first intercourse $A O R$} & \multirow{2}{*}{$\begin{array}{l}\text { Model } 1 \\
95 \% \mathrm{Cl}\end{array}$} & \multirow[b]{2}{*}{$P$ value } & \multirow[b]{2}{*}{ AOR } & \multirow{2}{*}{$\begin{array}{l}\text { Model } 2 \\
95 \% \mathrm{Cl}\end{array}$} & \multirow[b]{2}{*}{$P$ value } \\
\hline & & & & & \\
\hline \multicolumn{6}{|l|}{ Age difference between respondent and first sex partner } \\
\hline Same age & & & 1 & & 0.639 \\
\hline Partner younger than respondent & & & 1.40 & 0.70 to 2.81 & \\
\hline Respondent younger than partner & & & 1.04 & 0.79 to 1.37 & \\
\hline $\mathrm{N}$ unweighted & & 1432 & & & 1432 \\
\hline N weighted & & 805 & & & 805 \\
\hline
\end{tabular}

AOR, adjusted odds ratio; $C l$, confidence interval; IMD, Index of Multiple Deprivation.

Natsal-2 researchers combining existing variables considered to be necessary for a healthy first sexual intercourse. The finding that age at first sex does not explain all of the variation observed in sexual competence, and nor does it account for the associations found with other antecedent factors, suggests that this measure is not merely a function of age at first sex, but rather tapping into a distinct dimension of the experience in itself. These conclusions support the future use of this measure in research concerned with sexual behaviour among young people, and may represent an alternative indicator by which the effectiveness of interventions to improve sexual health can be assessed.

Acknowledgements Natsal-3 is a collaboration between University College London (London, UK), the London School of Hygiene and Tropical Medicine (London, UK), NatCen Social Research, Public Health England (formerly the Health Protection Agency), and the University of Manchester (Manchester, UK). The authors thank the study participants; the team of interviewers from NatCen Social Research; and operations and computing staff from NatCen Social Research.

Funding Natsal-3 was supported by grants from the Medical Research Council (www.mrc.ac.uk; G0701757) and the Wellcome Trust (www.wellcome.ac.uk; 084840), with contributions from the Economic and Social Research Council and Department of Health. MJP was funded by an ESRC PhD Studentship. The funders had no role in study design, data collection and analysis, decision to publish, or preparation of the manuscript.

Competing interests None declared.

Patient consent Not required.

Provenance and peer review Not commissioned; externally peer reviewed.

Open access This is an open access article distributed in accordance with the Creative Commons Attribution 4.0 Unported (CC BY 4.0) license, which permits others to copy, redistribute, remix, transform and build upon this work for any purpose, provided the original work is properly cited, a link to the licence is given, and indication of whether changes were made. See: https://creativecommons.org/licenses/by/4.0/.

\section{REFERENCES}

1 Carpenter LM, Garcia L. Virginity lost: an intimate portrait of first sexual experiences. Am J Sociol 2007;113:294-6.
2 Hawes ZC, Wellings K, Stephenson J. First heterosexual intercourse in the United kingdom: a review of the literature. $J$ Sex Res 2010;47(2):137-52.

3 Halpern CT. Reframing research on adolescent sexuality: healthy sexual development as part of the life course. Perspect Sex Reprod Health 2010;42:6-7.

4 Ingham R, Van Zessen G. From individual properties to interactional processes. Sexual interactions and HIV risk: new conceptual perspectives in European research 1997:83-99.

5 Vanwesenbeeck I, Zessenz Gvan, Ingham R, et al. Factors and processes in heterosexual competence and risk: an integrated review of the evidence. Psychol Health 1999;14:25-50.

6 Wellings K, Nanchahal K, Macdowall W, et al. Sexual behaviour in Britain: early heterosexual experience. Lancet 2001;358:1843-50.

7 WHO. Defining sexual health: report of a technical consultation on sexual health. Geneva, 2006:28-31.

8 Else-Quest NM, Hyde JS, Delamater JD. Context counts: longterm sequelae of premarital intercourse or abstinence. J Sex Res 2005;42:102-12.

9 Reissing ED, Andruff HL, Wentland JJ. Looking back: the experience of first sexual intercourse and current sexual adjustment in young heterosexual adults. J Sex Res 2012;49:27-35.

10 Smith CV, Shaffer MJ. Gone but not forgotten: virginity loss and current sexual satisfaction. J Sex Marital Ther 2013;39:96111.

11 Palmer MJ, Clarke L, Ploubidis GB, et al. Is "sexual competence" at first heterosexual intercourse associated with subsequent sexual health status? J Sex Res 2017;54:91-104.

12 Erens B, Phelps A, Clifton S. The third National Survey of Sexual Attitudes and Lifestyles (Natsal-3): technical report, 2013.

13 Payne RA, Abel GA. UK indices of multiple deprivation-a way to make comparisons across constituent countries easier. Health Stat Q 2012;53:22-37.

14 Wight D, Parkes A, Strange V, et al. The quality of young people's heterosexual relationships: a longitudinal analysis of characteristics shaping subjective experience. Perspect Sex Reprod Health 2008;40:226-37.

15 Henderson M, Wight D, Raab G, et al. Heterosexual risk behaviour among young teenagers in Scotland. J Adolesc 2002;25:483-94.

16 Layte R, McGee H. Regret about the timing of first sexual intercourse: the role of age and context: Working Paper, The Economic and Social Research Institute (ESRI). Dublin 2007. 
17 Smiler AP, Ward LM, Caruthers A, et al. Pleasure, empowerment, and love: factors associated with a positive first coitus. Sex Res Social Policy 2005;2:41-55.

18 Social Exclusion Unit. The teenage pregnancy strategy The Stationary Office Ltd, 1999.

19 Wight D, Williamson L, Henderson M. Parental influences on young people's sexual behaviour: a longitudinal analysis. $J$ Adolesc 2006;29:473-94.

20 Blenkinsop S, Wade P, Benton T, et al. Evaluation of the APAUSE SRE Programme: National Foundation for Educational Research UK, 2004.

21 Bosma H, Schrijvers C, Mackenbach JP. Socioeconomic inequalities in mortality and importance of perceived control: cohort study. BMJ 1999;319:1469-70.

22 Bailis DS, Segall A, Mahon MJ, et al. Perceived control in relation to socioeconomic and behavioral resources for health. Soc Sci Med 2001;52:1661-76.

23 Wayal S, Hughes G, Sonnenberg P, et al. Ethnic variations in sexual behaviours and sexual health markers: findings from the third British National Survey of Sexual Attitudes and Lifestyles (Natsal-3). Lancet Public Health 2017;2:e458-e472.

24 Schubotz D, Rolston B, Simpson A. Sexual behaviour of young people in Northern Ireland: first sexual experience. Crit Public Health 2004;14:177-90.
25 Ingham R, Woodcock A, Stenner K. Getting to know you young people's knowledge of their partners at first intercourse. J Community Appl Soc Psychol 1991;1:117-32.

26 Holland J, Ramazanoglu C, Sharpe S, et al. Deconstructing virginity-young people's accounts of first sex. Sex Relation Ther 2010;25:351-62.

27 Hyde A, Drennan J, Howlett E, et al. Heterosexual experiences of secondary school pupils in Ireland: sexual coercion in context. Cult Health Sex 2008;10:479-93.

28 Sonnenberg P, Clifton S, Beddows S, et al. Prevalence, risk factors, and uptake of interventions for sexually transmitted infections in Britain: findings from the National Surveys of Sexual Attitudes and Lifestyles (Natsal). The Lancet 2013;382:1795-806.

29 Wellings K, Jones KG, Mercer CH, et al. The prevalence of unplanned pregnancy and associated factors in Britain: findings from the third National Survey of Sexual Attitudes and Lifestyles (Natsal-3). The Lancet 2013;382:1807-16.

30 Mercer CH, Tanton C, Prah P, et al. Changes in sexual attitudes and lifestyles in Britain through the life course and over time: findings from the National Surveys of Sexual Attitudes and Lifestyles (Natsal). The Lancet 2013;382:1781-94. 